\title{
Christine Budzikiewicz
}

\section{Materielle Statuseinheit und kollisionsrechtliche Statusverbesserung}

Zu der Rechtsstellung des außerehelich geborenen Kindes unter Berücksichtigung der Folgen für das Kollisionsrecht der Legitimation

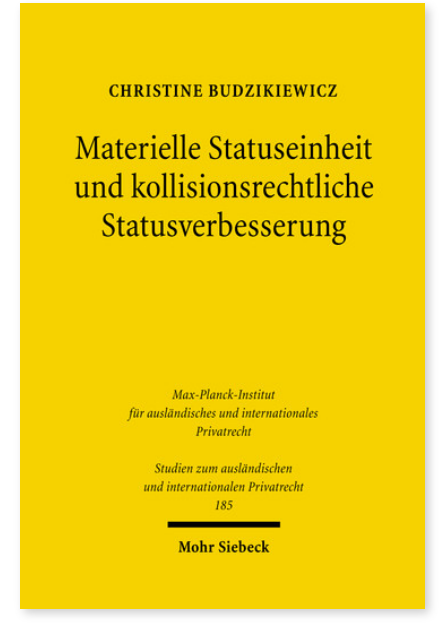

2007. XXVII, 443 Seiten. StudIPR 185

ISBN 978-3-16-151370-1

DOI 10.1628/978-3-16-151370-1

Book PDF 104,00€

ISBN 978-3-16-149147-4

fadengeheftete Broschur 104,00€
Christine Budzikiewicz setzt sich mit der Stellung des außerehelich geborenen Kindes nach Inkrafttreten des Kindschaftsrechtsreformgesetzes am 1.7.1998 auseinander. Ziel der Reform war die Beseitigung der bisherigen Statusunterschiede zwischen ehelichen und nichtehelichen Kindern und damit die Schaffung eines einheitlichen Kindschaftsrechts. Zugleich wurde das auf eine Statusverbesserung des Kindes zielende Institut der Legitimation aufgegeben. Aufgehoben wurden jedoch nicht nur die betreffenden Regelungen des materiellen Familienrechts, sondern sämtliche das Institut in Bezug nehmenden Vorschriften einschließlich der maßgeblichen Kollisionsnorm (Art. 21 EGBGB a.F.). Die Autorin fragt, wie die Rechtsfigur der Legitimation, die sich noch immer in zahlreichen ausländischen Rechtsordnungen findet, im Inland künftig zu behandeln ist. Dabei untersucht sie zunächst, in welchem Umfang die Eheschließung der Eltern auch weiterhin die Rechtsstellung des Kindes beeinflussen kann. Beleuchtet werden in diesem Zusammenhang das Familien- und Erbrecht ebenso wie das Staatsangehörigkeits- und das Personenstandsrecht. Die Frage der Anknüpfung der Legitimation wird im zweiten Teil des Buches behandelt. Eingeleitet wird dieser durch eine rechtsvergleichende Darstellung derjenigen europäischen Rechtsordnungen, in denen wie im deutschen Recht die Legitimation abgeschafft wurde, die sich aber dennoch mit der kollisionsrechtlichen Beachtlichkeit der Rechtsfigur auseinandergesetzt haben. Im Anschluss entwickelt die Autorin eine Lösung der Problematik für das deutsche Internationale Privatrecht.

Christine Budzikiewicz Geboren 1971; Studium der Rechtswissenschaften in Köln, Lausanne und Bonn; 2005 Promotion; wiss. Mitarbeiterin am Institut für internationales und ausländisches Privatrecht der Universität Köln.

Jetzt bestellen:

https://mohrsiebeck.com/buch/materielle-statuseinheit-und-kollisionsrechtliche-statusverbesserung-9783161513701? no cache $=1$

order@mohrsiebeck.com

Telefon: +49 (0)7071-923-17

Telefax: +49(0)7071-51104 